УДК 346.6, 336.225.4

DOI https://doi.org/10.32837/pyuv.v0i2(27).201

\author{
Н. С. Пирога \\ кандидат юридических наук, \\ докторант кафедры конституционного права и сравнительного правоведения \\ Ужгородского национального университета
}

\title{
СПРАВЕДЛИВАЯ РЫНОЧНАЯ СТОИМОСТЬ - БАЗОВЫЙ ЭЛЕМЕНТ НАЛОГОВОЙ СИСТЕМЫ
}

Производство и движение товара в сфере предпринимательской деятельности можно рассматривать в двух аспектах: с точки зрения затрат и с позиции результата. Издержки производства - затраты, связанные с производством и обращением произведенных товаров, в бухгалтерской и статистической отчетности отражаются в виде себестоимости. Общая классификация производственных издержек включает массу пунктов, основными из которых являются: альтернативные, экономические, бухгалтерские, постоянные и переменные издержки [1]. В зависимости от того, в каком масштабе они рассматриваются, можно выделить индивидуальные издержки - для отдельной фирмы и общественные - с точки зрения всей государственной экономики.

Наибольший удельный вес во всех расходах предприятий занимают затраты на производство продукции. Совокупность производственных затрат показывает, во что обходится предприятию изготовление выпускаемой продукции. По экономическим элементам затраты предприятия включают в себя пять основных групп:

- материальные затраты;

- затраты на оплату труда;

- отчисления на социальные нужды или отчисления во внебюджетные социальные фонды (пенсионный, фонд социального страхования, государственный фонд занятости, фонды обязательного медицинского страхования).

- амортизация основных фондов;

- прочие затраты.

В настоящее время важнейшим качественным показателем, отражающим в обобщенном виде все стороны хозяйственной деятельности предприятий (фирм, компаний), их достижения и недостатки, считается себестоимость. Себестоимость - все издержки (затраты), понесённые предприятием на производство и реализацию (продажу) продукции или услуги. Смысл этого показателя в плановой экономике сводился к тому, что можно планировать снижение себестоимости и привязать цену реализации к её показателю. Но в рыночной экономике нет внешних планов по снижению себестоимости и нет никакой привязки цены к ней. Тут действует совсем иной механизм ценообразования. С другой стороны, не известны в мире производства, цель деятельности которых состоят в снижении себестоимости или ограничении цены определенной надбавкой к себестоимости. Цена в рыночной экономике определяется балансом спроса и предложения, который устанавливается на рынке с учетом государственного регулирования. Поэтому себестоимость оценивает процесс, но не результат.

Себестоимость не является универсальным показателем и не включает затраты капитала, необходимые для производства материальных благ. Показатель себестоимости относится к конкретному товару/услуге. Нельзя сравнивать себестоимость автомобиля и телевизора, хлеба и мяса и т.д. и т.п.

Целью статьи является обоснование выбора объективного показателя, который отражает результаты хозяйственной деятельности, определяет стимулы потенциальным поставщикам материальных благ для рационального использования ресурсов и капитала и является единственным источником доходов предпринимателей, рабочих и государства.

Современная экономическая теория сохраняет исходное положение об издержках производства: чтобы получить большее количество любого блага, необходимо предоставить потенциальным производителям и поставщикам этого блага определенный стимул, который бы побудил их перебросить ресурсы из сферы их текущего использования на производство того, чего мы хотим. Необходимо, чтобы выгоды от такой переброски превысили затраты на нее, т.е. превысили ценность тех возможностей, от которых придется отказываться потенциальным предпринимателям.

Всю жизнь стимулы заставляют нас совершать определенныепоступки. Владельцысобственности хотят установить, по возможности, более высокие цены на свои ресурсы. Рабочие ищут наивысшую зарплату. Желание повысить свое благосостояние побуждает их работать эффективнее и производительнее. Бизнесмен стремится к высоким прибылям. Стимулом производственной деятельности является заработная плата (фонд оплаты труда) и прибыль. Сумма фонда труда и прибыли является вновь созданной добавленной стоимостью - отражает результат производственной деятельности.

Добавленная стоимость конечного продукта определяется суммой добавленной стоимости, 
созданной на каждой стадии производственного цикла. Добавленная стоимость позволяет установить или определить справедливую рыночную цену любого товара и обеспечить эквивалентный обмен различных товаров/услуг, ориентируясь на величину добавленной стоимости. Добавленная стоимость товара/услуги отличается от их рыночной стоимости. Рыночная стоимость определяется конечным потребителем путем сравнения потребительских свойств товара/услуги и их добавленной стоимости. Рыночная оценка потребителем добавленной стоимости товара в разных валютах позволяет определить реальный обменный курс по отдельным видам товаров/услуг. Эта оценка дает объективные критерии для выработки управленческих решений на различных уровнях: от цеха, производящего товар/услугу, и до министерства, управляющего отдельной отраслью экономики.

Добавленная стоимость, созданная на каждом этапе производственного цикла движения товаров/услуг до конечного потребителя, является единственным объективным показателем уровня развития экономики, единственным стимулом ее развития и единственным источником доходов государства, которые извлекаются в виде налогов. $\mathrm{C}$ потерей добавленной стоимости теряется и суверенитет страны. С ростом добавленной стоимости растут благосостояние граждан, возможности страны, в том числе по формированию и защите своего суверенитета [2]. Качественный показатель «себестоимость продукции» подлежит замене на объективный показатель «добавленная стоимость» как для отдельного товара/услуги, так и для отрасли и экономики в целом. Суммарная добавленная стоимость, созданная на протяжении года, определяет валовый внутренний продукт (ВВП) страны. В Украине объективная оценка ВВП возможна только методом добавленной стоимости (производственным методом). Другие методы (по доходам или по расходам) дать объективную оценку не могут в принципе.

По экономическим элементам добавленная стоимость представляет сумму фонда оплаты труда и прибыли как составляющие издержек производства. Западные экономисты считают издержками все платежи - внешние и внутренние, включая в издержки и нормальную прибыль, необходимые для того, чтобы привлечь и удержать ресурсы в пределах данного направления деятельности. А. Смит (1993) в труде «Исследование о природе и причинах богатства народов» утверждал: «Стоимость, которую рабочие прибавляют к стоимости материалов, распадается сама <..> на две части, из которых одна идет на оплату их заработной платы, а другая - на оплату прибыли их предпринимателя на весь капитал, который он авансировал в виде материалов и заработной платы» [3]. Д. Рикардо [4] сформулировал закон, согласно которо- му величины заработной платы и прибыли находятся в обратной пропорциональной зависимости.

Фонд оплаты труда включает:

- выплаты заработной платы за фактически выполненную работу в соответствии с тарифными ставками, должностными окладами и др.;

- стоимость продукции, выдаваемой в порядке натуральной оплаты работникам;

- премии, надбавки к окладам за производственные результаты;

- стоимость бесплатно предоставляемых работникам отдельных отраслей в соответствии с законодательством коммунальных услуг, питания, форменной одежды, жилья и др.;

- оплата очередных (ежегодных) и учебных отпусков;

- выплаты работникам, высвобождаемым с предприятий в связи с реорганизацией, сокращением штатов и др.

- отчисления на социальные нужды или отчисления во внебюджетные социальные фонды (пенсионный, фонд социального страхования, государственный фонд занятости, фонды обязательного медицинского страхования).

В соответствии с принятой методикой в состав добавленной стоимости, наряду с созданными на предприятиях эквивалентами доходов, входят ещё и амортизационные отчисления, потому что они рассматриваются как фактор, создающий стоимость продукции [5]. Некоторые авторы включают в добавленную стоимость и другие составляющие: ренту, проценты на кредит, расходы на рекламу и т.п. [6] С нашей точки зрения, расходы на рекламу незаконно включать даже в затраты производства, не то что в добавленную стоимость. Реклама должна финансироваться исключительно из остатка прибыли после уплаты налога на прибыль. Если реклама увеличивает чистую прибыль, то из этой прибыли она должна и финансироваться. Что касается других составляющих (рента, проценты на кредит, амортизация и т.д., и т.п.), то они отражены в показателе прибыль. Ибо прибыль - это доход на такой фактор производства, как капитал, вложенный в производство товара/услуги, точно так же как фонд оплаты труда можно считать доходом на фактор производства - труд. С другой стороны, рента, проценты на кредит - это чья-то прибыль. Для исключения повторного счета при определении ВВП эти составляющие нельзя включать в добавленную стоимость товаров/услуг. Ни при каких условиях амортизация не может причисляться к добавочной стоимости. На этапе использования основного капитала амортизация относится к затратам - уменьшает стоимость основного капитала, рациональное использование которого вознаграждается прибылью. С другой стороны, амортизация - это возвратный капитал, который отра- 
жается на отдельном счете - «амортизационные отчисления». Уменьшение остатка на этом счете может происходить в результате использования начисленной амортизации на капитальные инвестиции, на погашение кредитов, взятых на капитальные инвестиции и т.д.

Анализ показывает, что, с точки зрения результата, стимула и источника доходов, добавленная стоимость (ДС) должна включать только две составляющие:

$$
\text { ДС = фонд оплаты труда + прибыль. }
$$

Добавленная стоимость позволяет определить справедливую рыночную стоимость (СРС) товара/ услуги:

$$
\mathrm{CPC}=\text { ДС }+ \text { НДС }+ \text { амортизация }+ \text { затраты. }
$$

Затраты, конечно, можно делить на материальные и прочие затраты, на постоянные и переменные, альтернативные, экономические, бухгалтерские и т.п. Для определения величины затрат производства в этом нет необходимости. Реальные затраты производства следует определять по величине НДС, уплаченного непосредственно в бюджет при приобретении товаров/услуг, использованных в производстве:

$$
\text { Затраты }=\mathrm{HДC}_{\text {уплаченный }} / \mathrm{Ч}_{\mathrm{HдC}}
$$

где $\mathrm{Ч}_{\text {ндс }}=\mathrm{C}_{\text {ндс }} /\left(100+\mathrm{C}_{\text {ндс }}\right)$ - доля НДС в цене приобретаемого товара/услуги; $\mathrm{C}_{\text {ндс }}$ - действующая ставка НДС, в процентах. Эта формула определяет также начальную стоимость объектов амортизации по величине НДС, уплаченного в бюджет при их приобретении.

В формуле для определения справедливой рыночной стоимости неизвестна одна величина прибыль производителя (доходы на использование фактора капитал). Изначально эта величина могла бы быть задана как нормальная прибыль на единицу вложенного капитала - основной и оборотный капитал. Основной капитал - это остаточная стоимость основных фондов, использованных в производстве данного товара, при условии их эффективного использования при двухсменной загрузке. Оборотный капитал - это минимальные оборотные средства, необходимые для организации ритмичной работы. Тут не следует учитывать происхождение (источник) оборотного капитала собственные средства или заемные. На собственные средства производитель получает прибыль, на заемные средства прибыль получает кредитор. Конечно, норма прибыли на единицу вложенного капитала зависит от отрасли, к которой относится производство. Межотраслевая конкуренция объективно создает определенное динамичное равновесие, обеспечивающее получение примерно равной прибыли на равный капитал, независимо от того, где он вложен. В американской экономике различия в отраслевых нормах прибыли составляют всего лишь 1-2 процента. В Украине конкурен- ции никакой нет (значительная часть экономики монополизирована), а структура экономики сильно деформирована. Поэтому какое-то влияние государства на величину нормы прибыли в различных отраслях должно быть внедрено.

Конечно, предварительные расчеты справедливой рыночной стоимости должны найти подтверждение на рынке. Если покупатель согласен с предложенной ценой, товар/услуга найдет потребителя на рынке. Если реализация невозможна, цену придется снижать, что свидетельствует о неправильной оценке добавленной стоимости, завышенных затратах производства или нерациональном распределении добавленной стоимости между фондом оплаты труда и прибылью.

Воспользовавшись монопольным положением на рынке, производитель может предложить завышенную цену. В этом случае рыночную добавленную стоимость можно определить, воспользовавшись соотношением:

ДС $\times\left(1+\mathrm{C}_{\mathrm{Hдc}} / 100\right)=\mathrm{PC}-$ Затраты - Амортизация,

где РC - рыночная стоимость, по которой фактически реализуется товар, затраты и начальную стоимость объектов амортизации определяем по величине НДС, уплаченного при их приобретении в бюджет. Из этого равенства определяется добавленная стоимость и НДС = ДС $\square \mathrm{C}_{\text {ндс }}$, подлежащий к уплате в бюджет в момент реализации.

На рынке всегда присутствуют три субъекта: производитель, потребитель и государство. Для удовлетворения интересов всех необходимо обеспечить платежеспособный спрос на товары/ услуги и уплату всех предусмотренных законодательством налогов и сборов. Обеспечение платежеспособного спроса предполагает установление разумных пропорций распределения добавленной стоимости, при которых возможно установление баланса спроса и предложения и обеспечение производства определенного количества товаров. Для получения всех законно установленных налогов необходимо отсутствие теневого производства (теневой добавленной стоимости). Теневая экономика всегда связана с наличием свободных производственных мощностей и чрезмерным налоговым прессом. В украинской экономике и свободных производственных мощностей предостаточно, и чрезмерный налоговый пресс, и низкая правовая культура. Это взаимосвязанные факторы. Чтобы получить необходимые средства, государство увеличивает налоговый пресс, убивая стимулы любого легального производства. Производитель на это отвечает уходом в тень. Соревнования законодателя и производителя надо прекратить, тем более что производитель всегда может купить право не исполнять закон, создавая новую проблему под названием «коррупция». В рейтинге по коррупции Украина и так на первом месте - выше призовых мест уже нет. 
C увеличением размера добавленной стоимости приумножается и собственность государства. Оценим взаимосвязь доходов государства и величины вновь созданной добавленной стоимости. Предположим, что в стране создана добавленная стоимость, которую примем за единицу. На эту добавленную стоимость начисляется НДС по ставке $20 \%$. Составляющие добавленной стоимости фонд оплаты труда и прибыль. Фонд оплаты труда является базой единого социального взноса (ЕCB) по ставке $22 \%$. Прибыль является базой налога на прибыль по ставке $18 \%$. Для определения налоговой нагрузки (доля доходов государства в добавленной стоимости) необходимо знать пропорции распределения добавленной стоимости между фондом оплаты труда и прибылью. Эти пропорции в Украине находятся далеко за пределами здравого смысла. Поэтому примем для расчета какое-то разумное распределение: например, фонд оплаты труда составляет $30 \%$ добавленной стоимости, прибыль - остальные $70 \%$. При таком распределении сумма налогов и сборов равна: $\mathrm{ECB}=0,3 \times 0,22=$ 0,066 ; налог на прибыль (НП) $0,7 \times 0,18=0,126$. База налога на доходы физических лиц (НДФЛ) определяется разностью фонда оплаты труда и отчислениями ЕСВ и облагается налогом по ставке $18 \%$. Налог на доходы физических лиц составляет: $(0,3-0,066) \times 0,18=0,0351$. Сумма НДС + $\mathrm{ECB}+$ НДФЛ $+\mathrm{H \Pi}=0,2+0,066+0,0351+$ $0,126=0,4271$, или $42,71 \%$ от созданной добавленной стоимости. Это и есть налоговая нагрузка на добавленную стоимость, созданную на определенном этапе производства. Суммируя добавленную стоимость по всей экономике страны, получаем налоговую нагрузку на ВВП - те же $42,71 \%$.

Согласно статистической отчетности, номинальный ВВП (добавленная стоимость) Украины в 2016 г. составил 2383,182 млрд грн. Налоговая нагрузка на ВВП, включающая НДС, налоги на доходы физических лиц, на прибыль и ЕСВ составляет $42,71 \%$. Следовательно, сумма доходов бюджета и взносов ЕСВ в 2016 г. должна была составить 1017,86 млрд грн. Реально в 2016 г. собрана сумма 721,7 млрд грн, в том числе: доходы государственного бюджета составили 616,3 млрд грн, поступления ЕСВ - 105,4 млрд грн. ${ }^{1}$ Недополучено налогов и сборов 296,16 млрд грн, что достаточно для перечисления дотации из госбюджета Пенсионному фонду - 142,9 млрд грн и покрытия дефицита государственного бюджета - 70,3 млрд грн ${ }^{2}$. Даже если в Украине не было бы никаких других налогов и сборов, при условии выполнения зако- нов государственный бюджет был бы выполнен с профицитом 115,9 млрд грн и была бы предоставлена дотация Пенсионному фонду в сумме 142,9 млрд грн.

Таким образом, если учесть только три налога: НДС, на прибыль, на доходы физических лиц и единый социальный взнос, суммарные утраты бюджета и Пенсионного фонда в 2016 г. составили 296,16 млрд грн, или $48 \%$ государственного бюджета. Если эту утрату считать неполученным налогом на обороты теневой экономики, то они составляют 693,42 млрд грн, или $29 \%$ ВВП. Но теневая экономика не включается в ВВП, a 693,42 млрд грн - это скрытые от налогообложения доходы легальной экономики.

В данный момент в теневой экономике в Украине в обращении находится около 1,1 триллиона грн ${ }^{3}$, что составляет почти половину ВВП 2016 г. Теневая экономика и коррупция - это почти синонимы. Коррупция - это плата за разрешение не исполнять законы, а теневая экономика - источник доходов для финансирования коррупции. Нет смысла бесконечно менять законы, придумывая новые налоги или увеличивая ставки существующих, с целью изъять в бюджет большую часть добавленной стоимости (ВВП), если те, кто призван контролировать их выполнение, зарабатывают на разрешении их не исполнять. Нет и большого смысла контролировать контролеров исполнения закона.

Для устранения отмеченных недостатков необходимо усовершенствовать методы исчисления и взимания налогов и сборов: НДС, на доходы физических лиц, на прибыль и на социальное страхование. С этой целью предлагаем внести следующие изменения в законодательство:

1) изменить объект налогообложения НДС, изложив п. 1 ст. 185 НКУ в следующей редакции:

185.1 Объектом налогообложения является добавленная стоимость;

2) устранить налоговые правоотношения между субъектами, предусмотрев уплату НДС непосредственно в бюджет на каждой стадии движения товара до конечного пользователя. Налоговые правоотношения могут существовать исключительно между государством и субъектами. В налоговых накладных указывать только сумму, которая уплачена в бюджет на предыдущих стадиях производственно-реализационного цикла, т.е. сумму НДС, подлежащую транзиту до конечного пользователя;

3) определить добавленную стоимость (ДС):

\footnotetext{
${ }^{1}$ http://www.pfu.gov.ua/pfu/doccatalog/document?id=277122.

${ }^{2}$ http://minfin.gov.ua/uploads/redactor/files/\% D0 $\%$ 9F $\%$ D1 $\%$ 80 $\%$ D0 $\%$ B5 $\%$ D0 $\%$ B7 $\%$ D0 $\%$ B5 $\%$ D0 $\%$ BD $\%$ D1 $\% 82 \%$

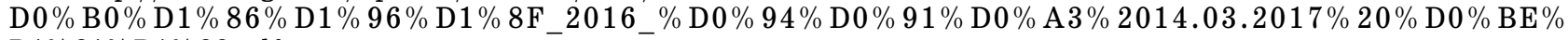
D1 $\%$ 81\% D1\% 82.pdf.

${ }^{3}$ http://blog.ubr.ua/finansy/tenevaia-ekonomika-ukrainy-o-eshe-odnom-provalennom-obeshanii-kabmina-14587.
} 


$$
\text { ДС = фонд оплаты труда + прибыль. }
$$

4) определить долю фонда оплаты труда как процент добавленной стоимости (например, 30\% ДС) и указать сроки ее достижения по годам - $20 \%$ в 2018 г.; 25\% - 2019 г. и т.д. При необходимости дифференцировать по секторам экономики;

5) рассчитать добавленную стоимость товаров/ услуг из уравнения:

ДС $\times\left(1+\mathrm{C}_{\text {ндС }} / 100\right)=\mathrm{PC}-$ Затраты - Амортизация,

где $\mathrm{PC}$ - рыночная стоимость, по которой фактически реализуется товар/услуга, затраты и начальную стоимость объектов амортизации определяем по величине НДС, уплаченного при их приобретении в бюджет;

6) определить базу единого социального взноса (ECB):

$$
\text { База }_{\mathrm{ECB}}=\text { фонд оплаты труда }=30 \% \text { ДС. }
$$

7) определить базу налога на прибыль:

$\mathrm{Б}_{\text {прибыль }}=$ ДС - фонд оплаты труда $=70 \%$ ДС.

8) определить базу налога на доходы физических лиц (НДФЛ):

$$
\mathrm{b}_{\text {ндФд }}=\text { фонд оплаты труда - ECB. }
$$

При ныне действующих ставках налогов: НДС, на прибыль, на доходы физический лиц и ЕСB изъятие составит $42,71 \%$ добавленной стоимости.

Объективным показателем, отражающим результаты производственной деятельности, определяющим стимулы потенциальным поставщикам материальных благ для рационального использования ресурсов и капитала и являющимся единственным источником доходов субъектов хозяйствования и государства, является добавленная стоимость и ее составляющие - фонд оплаты труда и прибыль. Проанализированы недостатки системы налогообложения и сформулированы изменения в законодательстве, которые позволят устранить имеющиеся недостатки.

\section{Jumepamypa}

1. Гальперин В.М., Игнатьев С.М., Моргунов В.И. Микроэкономика: В 2 т. Т. 1. / Общ. ред. В.М. Гальперина. Санкт-Петербург : Экономическая школа, 2000. $349 \mathrm{c}$

2. Тренев Н.Н. Добавленная стоимость как основа экономической безопасности. Национальные инте ресы: приоритеты и безопасность. 2013. № 14 (203). C. $33-40$.

3. Смит А. Исследование о природе и причинах богатства народов: в 2-х т. Т. 1 / пер. с англ. П. Клюкина. Москва : Эксмо, 2016. 496 с.

4. Рикардо Д. Начала политической экономии и налогового обложения. Сочинения : в 3-х т. / пер. с англ. П. Клюкина; под ред. Л. Амелехина. Москва : Эксмо, 2007. $960 \mathrm{c}$.

5. Бабина Г.М. Добавленная стоимость - ключевой фактор финансового здоровья предприятия. Экономи ка и управление. 2014. № 3 (39). С. 42-45.

6. Булатов А.С. Экономика : учебник. 3-е изд., перераб. и доп. Москва : Экономистъ, 2004. 896 с.

\section{Аннотация}

Пирога И. С. Справедливая рыночная стоимость базовый элемент налоговой системы. - Статья.

Добавленная стоимость является объективным показателем, отражающим результаты производственной деятельности, определяет стимулы потенциальным поставщикам материальных благ и является единственным источником доходов субъектов хозяйствования и государства. Добавленная стоимость позволяет установить или определить справедливую рыночную цену любого товара и обеспечить эквивалентный обмен различных товаров/услуг. Полная стоимость конечного продукта определяется суммой добавленной стоимости, созданной на каждой стадии производственного цикла. Товары/услуги приобретают определенную стоимость только после реализации потребителям. Рыночная оценка потребителем не влияет на структуру добавленной стоимости, которая определяется суммой факторных доходов производителя - фонда оплаты труда и прибыли, включая предпринимательский доход, процент и ренту. Добавленная стоимость, созданная на каждой стадии производственного цикла, равна разности рыночной стоимости товаров/услуг, затрат производства и амортизации оборудования. $\mathrm{K}$ издержкам производства относятся любые расходы, которые подтверждены суммой уплаченного НДС. Амортизационные отчисления начисляются по нормам Налогового кодекса Украины. Валовая выручка, уплаченный НДС и начисленная амортизация позволяют точно определить добавленную стоимость, созданную на каждой стадии цикла, то есть базу основных налогов. Налогообложение добавленной стоимости и ее составляющих по действующим в Украине ставкам определяет налоговую нагрузку на нее. Если принять, что фонд оплаты труда составляет $30 \%$ добавленной стоимости, прибыль - остальные 70\%, налоговая нагрузка составляет $42,71 \%$, то есть сумма уплаченных налогов (НДС, на прибыль, на доходы физических лиц) и единого социального взноса должна составлять $42,71 \%$ от величины созданной добавленной стоимости на каждой стадии цикла. Подытоживая добавленную стоимость всей экономики страны, получаем налоговую нагрузку на ВВП - те же 42,71\%. Предложенный способ начисления налоговых обязательств предельно упрощает администрирование основных налогов и единого социального взноса.

Ключевые слова: добавленная стоимость, НДС, прибыль, фонд оплаты труда, ВВП, социальное страхование, налоговая база, справедливая рыночная стоимость.

\section{Анотація}

Пирога I. С. Справедлива ринкова вартість - базовий елемент податкової системи. - Стаття.

Додана вартість є об'єктивним показником, що відображає результати виробничої діяльності, визначає стимули потенційним постачальникам матеріальних благ і є єдиним джерелом доходів суб'єктів господарювання та держави. Додана вартість дає змогу встановити або визначити справедливу ринкову ціну будь-якого товару і забезпечити еквівалентний обмін різних товарів/послуг. Повна вартість кінцевого продукту визначається сумою доданої вартості, створеної на кожній стадії виробничого циклу. Товари/послуги набувають певну вартість лише після реалізації споживачам. Ринкова оцінка споживачем не впливає на структуру доданої вартості, яка визначається сумою факторних доходів виробника - фонду оплати праці і прибутку, що включає підприємницький дохід, відсоток і ренту. 
Додана вартість, створена на кожній стадії виробничого циклу, дорівнює різниці ринкової вартості товарів/ послуг, затрат виробництва і амортизації обладнання. До витрат виробництва належать будь-які витрати, які підтверджені належною сумою сплаченого ПДВ. Амортизаційні відрахування нараховуються за нормами Податкового кодексу України. Валова виручка, сплачений ПДВ і нарахована амортизація дають змогу точно визначити додану вартість, створену на кожній стадії циклу, тобто базу основних податків. Оподаткування доданої вартості і її складників за діючими в Україні ставками визначає податкове навантаження на неї. Якщо прийняти, що фонд оплати праці становить $30 \%$ доданої вартості, прибуток - решту $70 \%$, податкове навантаження становить $42,71 \%$, тобто сума сплачених податків (ПДВ, на прибуток, на доходи фізичних осіб) і єдиного соціального внеску має становити $42,71 \%$ від величини створеної доданої вартості на кожній стадії циклу. Підсумовуючи додану вартість всієї економіки країни, отримуємо податкове навантаження на ВВП - ті самі 42,71\%. Запропонований спосіб нарахування податкових зобов'язань гранично спрощує адміністрування основних податків і єдиного соціального внеску.

Ключові слова: додана вартість, ПДВ, прибуток, фонд оплати праці, ВВП, соціальне страхування, податкова база, справедлива ринкова вартість.

\section{Summary}

Pyroha Y.S. Fair market value is a basic element of the tax system. - Article.

Value-added is an objective indicator that reflects the results of production activities, identifies incentives for potential suppliers of material goods and is the sole source of income for economic entities and the state. Value-added allows you to set or determine a fair market price for any product and to ensure an equivalent exchange of different goods / services. The total value of the final product is determined by the amount of value added created at each stage of the production cycle. Products / services get value only after they are sold to consumers. The market valuation by the consumer does not affect the value added structure, which is determined by the sum of factor income of the producer - the wage and income fund, which includes entrepreneurial income, interest and rent. The value added created at each stage of the production cycle is equal to the difference in the market value of the goods / services, the cost of production and depreciation of the equipment. Production costs include any costs that are confirmed by the proper amount of VAT paid. Depreciation charges are calculated according to the provisions of the Tax Code of Ukraine. Gross revenue, VAT paid and accrued depreciation make it possible to accurately determine the value added generated at each stage of the cycle, i.e. the base of basic taxes. Taxation of value added and its components at the rates in force in Ukraine determines the tax burden on it. Assuming that the payroll is $30 \%$ of value added, the profit is the remaining $70 \%$, the tax burden is $42,71 \%$, i.e. the amount of taxes paid (VAT, income, income of individuals) and a single social contribution should be $42,71 \%$ of value added at each stage of the cycle. Summing up the added value of the whole economy of the country, we get the tax burden on GDP - the same $42,71 \%$. The proposed method of calculating tax liabilities greatly simplifies the administration of basic taxes and a single social contribution.

Key words: added value, profit, wage fund, VAT, GDP, social insurance, tax base, fair market value. 